\section{BMJ Open} Ophthalmology

\title{
Assessing full thickness oral mucosal grafting: complications and postoperative outcomes in a broad collective of patients
}

\author{
Daniel Pilger (D) , Christoph von Sonnleithner, Eckart Bertelmann
}

\begin{abstract}
To cite: Pilger D, von Sonnleithner C, Bertelmann E. Assessing full thickness oral mucosal grafting: complications and postoperative outcomes in a broad collective of patients. BMJ Open Ophthalmology 2020;5:e000337. doi:10.1136/ bmjophth-2019-000337
\end{abstract}

DP and CvS contributed equally.

Received 20 May 2019

Revised 29 November 2019 Accepted 24 December 2019

\section{Check for updates}

(c) Author(s) (or their employer(s)) 2020. Re-use permitted under CC BY-NC. No commercial re-use. See rights and permissions. Published by BMJ.

Department of Ophthalmology, Charité - Universitätsmedizin Berlin, Berlin, Germany

Correspondence to Prof.

Eckart Bertelmann; eckart. bertelmann@charite.de

\section{ABSTRACT}

Background Conjunctival defects can be repaired with several mucosal tissues. The simplicity of harvesting oral mucosa and its wide availability makes it the preferred graft tissue for all indications requiring mucosal grafting. Through analysing the postsurgical outcomes and rate of revisions, this study explores the suitability of oral mucosa grafts, depending on the initial diagnosis.

Methods We reviewed all the files of patients with a history of oral mucosal graft surgery, performed at our clinic between 2012 and 2018, focusing on complications and revision rates.

Results In total, we analysed 173 oral mucosa grafts in 131 patients. The most common initial diagnosis was tumour resection, followed by surgical complications, postenucleation socket syndrome, trauma and ocular surface disorders. Complication and revision rates depended highly on the initial diagnosis. Revision rates were highest if the initial diagnosis included ocular surface disorders or chemical trauma.

Conclusions Oral mucosa grafting (OMG) is the most effective treatment for a wide range of ocular conditions involving conjunctival defects. Conjunctival defects that result from trauma or cicatricial surface diseases seem less suitable for $\mathrm{OMG}$ and may benefit from alternative graft tissue or treatment options.

\section{INTRODUCTION}

Mucosal grafting in periorbital reconstruction is a well-established surgical technique for the treatment of conjunctival deficiencies and scaring. The most commonly used mucosa types are oral, labial or nasal. Oral mucosa has similar biological properties to the conjunctiva. Both tissues consists of one or more layers of epithelial cells overlying a layer of loose connective tissue. Oral mucosa, however, is thicker and can be pigmented. It can be harvested repeatedly, and its donor site is easily accessible and is widely available. Donor site morbidity is low ${ }^{1}$ and the surgery is generally well tolerated by patients. ${ }^{2}$ In addition, the surgical technique is relatively easy, rendering oral mucosa an ideal candidate for the replacement of conjunctival defects.

\section{Key messages}

What is already known about this subject?

- Conjunctival defects can be repaired with several mucosal tissues but the simplicity of harvesting oral mucosa and its availability makes it the preferred graft tissue.

\section{What are the new findings?}

This study shows that good results can be obtained by using oral mucosa as the primary tissue for the reconstruction of conjunctiva independent of the reason for grafting.

\section{How might these results change the focus of research and clinical practice? \\ - Mucosa grafting can be facilitated by choosing oral mucosa even in complex cases and other types of tissue might only be considered in rare instances.}

Oral mucosal grafts have not only been used in the treatment of contracted sockets in anophthalmic patients ${ }^{3-7}$ and in ocular surface and fornix reconstruction in patients after tumour resection, ${ }^{8}{ }^{9}$ but also in therapy refractive pterygia ${ }^{10} 11$ and in patients with ocular pemphigoid ${ }^{12} 13$ or symblephara. ${ }^{1415}$ It is also the tissue that is most commonly used in the treatment of postsurgical complications, including conjunctival insufficiencies after glaucoma, ${ }^{16}{ }^{17}$ retinal surgery, ${ }^{18}$ keratoprothesis-related corneal melts ${ }^{1920}$ and in lining the dacryocystorhinostomy tract. ${ }^{21}$ In addition, buccal mucosa has been used for the repair of intractable sclerocorneal melts caused by serious chemical burns. ${ }^{22}$

Compared with the oral mucosa, harvesting labial or nasal mucosa is more traumatic and can lead to more complications and discomfort. ${ }^{1}$ In contrast, nasal mucosa has the additional advantage of containing goblet cells that can increase the lubrication of the eye. ${ }^{23}$ Nasal mucosa grafting has shown good results in the treatment of severe mucus 
deficiency syndromes ${ }^{24}$ and labial tissue has successfully been used in patients with severe dry eye syndrome due to Stevens-Johnson syndrome or chemical burns. ${ }^{25} 26$

Besides mucosal tissues, the amniotic membrane is an alternative tissue that can be used in the ocular reconstruction. The tissue has been used to cover defects after tumour excision ${ }^{152728}$ but also in combination with oral mucosa grafting (OMG) in the treatment of severe symblephara. ${ }^{14}$ The use of amniotic membrane has the advantage of being less invasive and it has been suggested that due to the thinness of the membrane, monitoring tumour recurrence is facilitated. ${ }^{2728}$ Structural support of OMG, however, is higher and hence OMG can be used in a wider variety of indications. ${ }^{1}$

The simplicity of harvesting oral mucosa and its wide availability makes it the preferred graft tissue for all indications requiring mucosa grafting. Long-term outcomes, however, have been sparse and little is known about the suitability of this tissue when it is used in the treatment across different indications. Therefore, we exclusively performed oral mucosa grafts covering a broad spectrum of ophthalmological indications. Through analysing the postsurgical outcomes and rate of revisions, we are able to give clinically based recommendations for the suitability of oral mucosa grafts, depending on the initial diagnosis.

\section{METHODS}

In this retrospective, observational study, we reviewed all files form patients with a history of oral mucosal graft surgery, performed at our clinic between 2012 and 2018 . Cases were reviewed and details about the initial diagnosis, surgical procedure, complications and follow-up examinations were recorded. The follow-up of patients was passive via our outpatient clinic. This meant that patients had regular follow-up visits at least annually since the surgery and up to 5 years postsurgery.

All data were entered into a database and IBM SPSS statistics was used for data categorisation and analysis. We grouped similar diagnoses into larger categories to facilitate the analysis and presentation of data.

All patients received mucosal grafting performed by the same surgeons (E.B. or C.v.S.). As the surgery is performed under general anaesthesia, the endotracheal tube is placed on one side of the mouth to ensure a precise excision of oral mucosa on the other side (inner part of the cheek). The amount of oral mucosa required is estimated in accordance with the defect, taking into account a postoperative shrinking of the graft. The area of excision is chosen carefully to avoid damaging the parotid duct, which is normally located opposite the second upper molar. The area of excision is then marked with a surgical skin marker. Using local anaesthetic (Xylocitin 2\%, Lidocaine+Epinephrin), the mucosa is infiltrated to facilitate the excision and reduce bleeding. A scalpel is used to incise the border of the previously marked mucosal graft, followed by the use of scissors to detach the graft completely. After careful haemostasis with bipolar coagulation forceps, the wound is closed with 5-0 Vicryl sutures. Finally, the oral mucosa graft is thinned out with scissors, paying careful attention not to perforate the graft and the oral mucosa is prepared to be transplanted to the required area.

\section{Patient and public involvement}

There was no patient involvement in planning and executing this study. We are planning to inform future patients when planning OMG surgeries and the public via the presentation of our findings on congresses and through publication.

\section{RESULTS}

Between 2012 and 2018 we performed 173 mucosal graft surgeries in 74 men (56\%) and $57(44 \%)$ women, with a combined mean age of 57 years (SD 20 years). The mean follow-up time was 3.1 years (SD 2.2 years). Every patient had at least one follow-up visit approximately 1 year after the surgery. No patient was lost to follow-up immediately after surgery.

Figure 1 shows the primary diagnosis, indicating the need for mucosal graft surgery. Over half of all the patients were patients with tumour, with squamous cell carcinoma being the most common diagnosis (46\%), followed by malignant melanoma $(28 \%)$ and basalioma $(6 \%)$. Rare diagnoses were carcinoma in situ, conjunctival naevi, conjunctival melanosis, benign hyperplasia of the conjunctiva, adenocarcinoma and tumour of the caruncle. These patients were treated by removing the tumour, followed by mucosal grafting (figure 2). In 10 cases, the excision of the tumour was combined with a corrective lid-surgery. Only in four cases, tumour size and location allowed for radiotherapy prior to tumour excision.

The second most frequent diagnosis that required mucosal graft surgery was surgical complications. Here, the most frequent surgery that required correction by mucosal grafting was a pterygium surgery $(6,33 \%)$, either because of recurrence or because of symblephara. Accordingly, patients were treated with surgical excision or symblepharolysis with mucosal grafting (figure 3). The second most common surgery requiring mucosal grafting was trabeculectomy $(4,22 \%)$. Two patients with tenon's cysts were treated by removing the cyst and mucosal patching and in two other patients, conjunctival insufficiencies were patched with mucosal grafts. Furthermore, conjunctival defects due to prior surgery were seen in patients with, Ahmed valve (4), after pars plana vitrectomy (2), after radiation (1) and after lid surgery (1). All patients were successfully treated with mucosal grafting.

Equally frequent was a patient who had undergone enucleation. In 10 cases, patients had undergone enucleation due to phthisis bulbi, in 4 patients enucleation was performed due to uncontrollable secondary glaucoma and in 3 cases enucleation followed a severe trauma. None of the cases had a history of ocular tumours. In the majority of cases, we performed a fornix reconstruction with mucosal graft or OMG-fat 


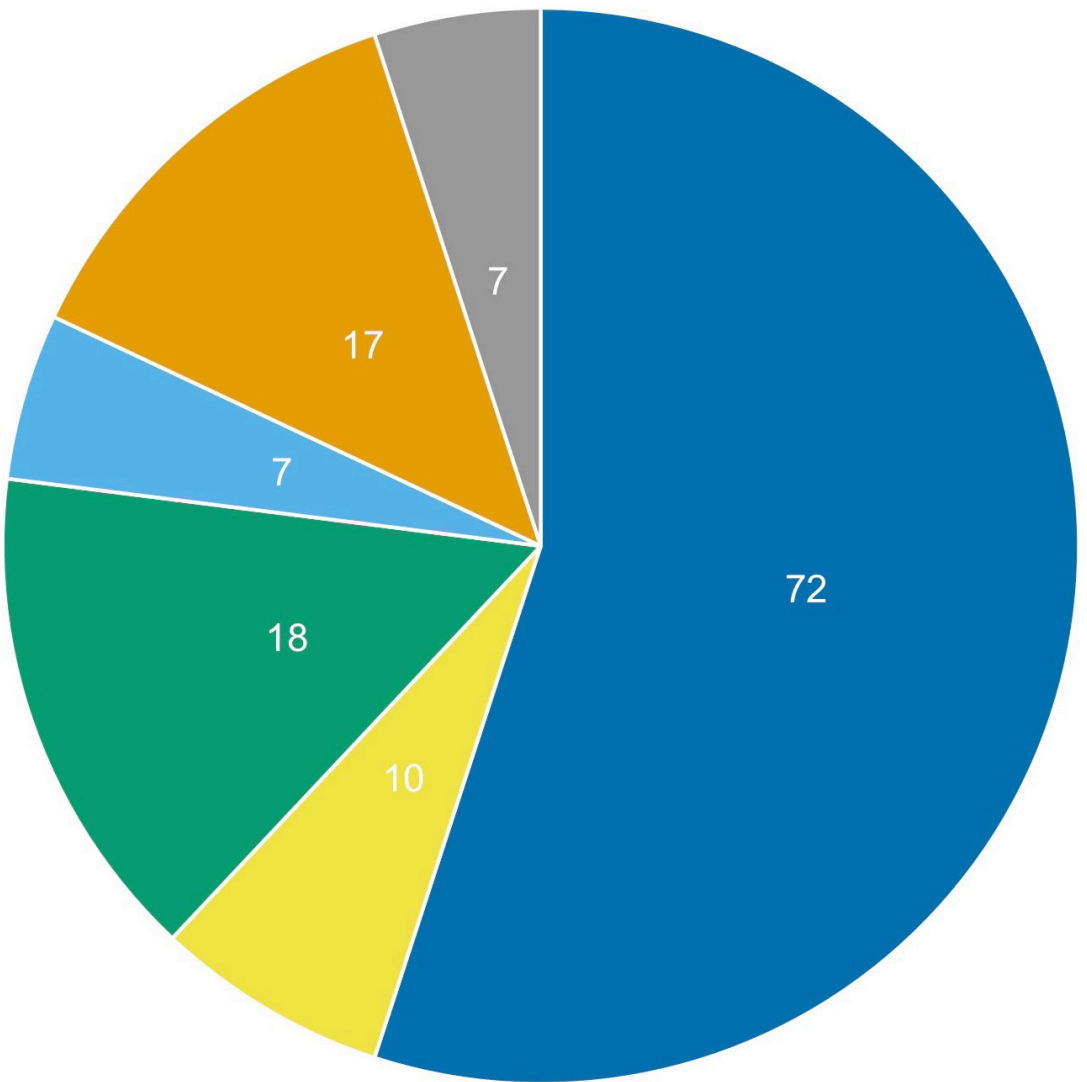

Cicatricial ocular surface diseases Enucleation

Other

Surgical complications

Trauma

Tumour

Figure 1 Frequency of OMG surgery by the initial diagnosis. OMG, oral mucosa grafting.

graft to treat orbital volume deficits. In three patients, who had undergone enucleation due to a trauma, we performed a symblepharolysis with fornix reconstruction and mucosal grafting.

In patients who had suffered injuries, we performed mucosal grafting to treat four patients with acid burns, four patients with heat burns and two patients after explosive trauma. All patients were treated with symblepharolysis or fornix reconstruction and mucosal grafting.

Patients with cicatricial ocular surface disease consisted of four patients with ocular pemphigoid, two patients with Stevens-Johnson syndrome and one patient with Lyell syndrome. Two patients with ocular pemphigoid received mucosal grafting as part of a keratoprothesis.
In the other two patients as well as in the patients with Stevens-Johnson syndrome, extensive symblephara were removed and patched with mucosal grafts (figure 4). One patient with Lyell syndrome showed pronounced atrophy of the conjunctiva and it was replaced with a mucosal graft.

Mucosal grafting was also used to treat the less common diagnosis. We treated three patients with congenital or post-traumatic lid deformities that had led to an atrophy of the conjunctiva because of insufficient lid closure. In one case, the removal of a conjunctival foreign body left a defect that had to be patched with oral mucosa and two cases of scleromalacia of unknown origin as well as one patient with a tear duct fistula were successfully treated with mucosal grafting (figure 5).

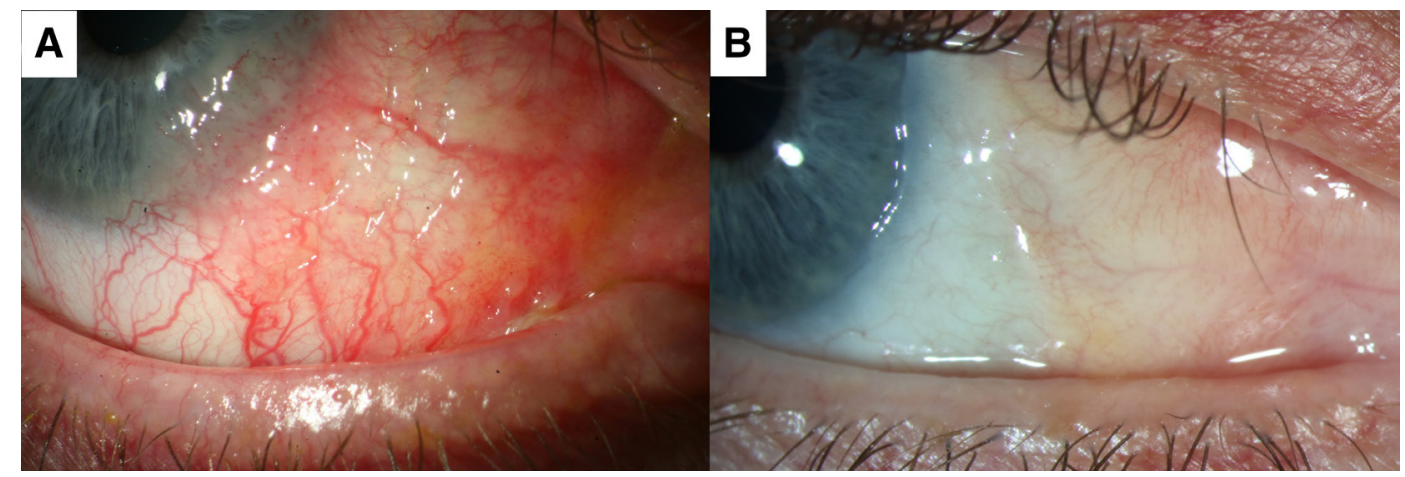

Figure 2 Patient with benign conjunctival hyperplasia 5 years after removal and patching with OMG. OMG, oral mucosa grafting. 


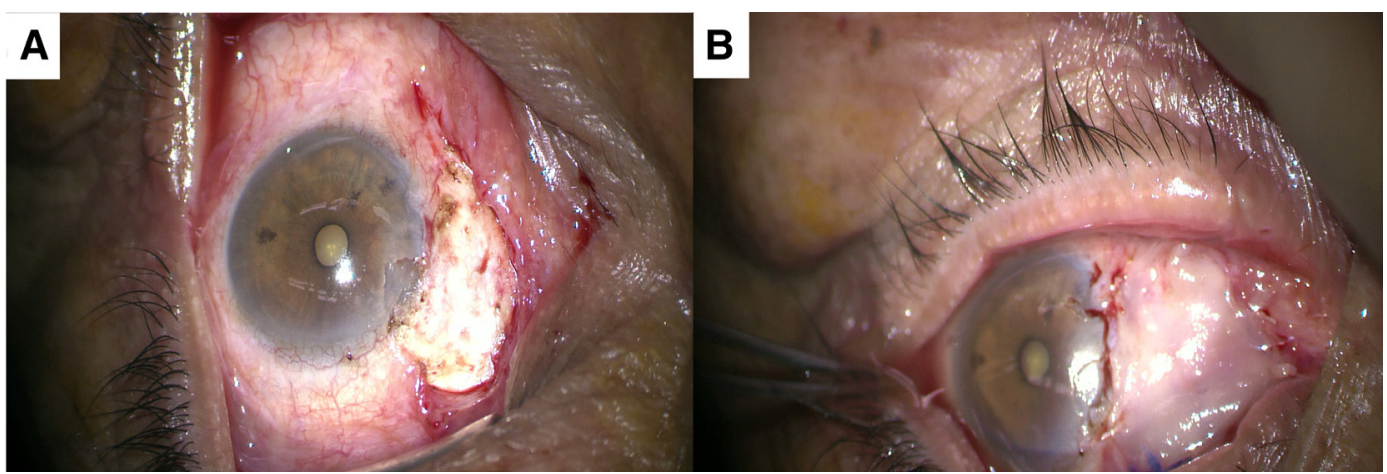

Figure 3 Therapy refractive pterygium patched with OMG. OMG, oral mucosa grafting.

\section{Complications}

The most common complication was symblephara. Symblephara developed in $66 \%$ of all surgeries, in patients with cicatricial ocular surface diseases, in $41 \%$ of all surgeries in patients that had sustained injuries, in $33 \%$ of all surgeries in postenucleation patients, and in $20 \%$ of all surgeries in patients with tumour.

Graft overgrowth occurred nine times but only in patients with tumour. These cases were monitored more frequently to assure that the overgrowth was not due to a tumour recurrence. In one case, overgrowth was surgically removed and tumour recurrence excluded by pathological analysis. None of the cases with overgrowth were due to tumour recurrence. Graft necrosis was observed only once.

\section{Revisions}

The majority of patients were successfully treated with a single surgery. None of the revision surgeries were due to cosmetic dissatisfaction. In 31 cases (24\%), a revision was required and among these cases, 7 patients had to undergo multiple revisions. Table 1 shows the frequency of revisions stratified by the initial diagnosis. Revision rates were highest in patients suffering from cicatricial ocular surface diseases, with almost every other patient requiring more than one surgery to remove symblephara. Similarly, almost half of all postenucleation patients required more than one surgery in order to successfully reconstruct the orbital socket. Revisions were required in one case due to, mucosal graft insufficiency, insufficient fornix reconstruction or to treat a postenucleation syndrome. Multiple revisions, however, were only observed if the patient was anophthalmic due to trauma (explosion or acid burns) or if the patient had an underlying surface disease (Sjörgen syndrome). Among patients with tumour, five patients underwent more than one surgery due to a tumour recurrence. In none of the cases, tumour recurrence occurred underneath the graft. Tumour recurrence did not depend on the type or size of the primary tumour or on prior radiotherapy (data not shown). Besides tumour recurrence postsurgical symblephara that led to the reconstruction of the fornix was another reason for additional surgery among patients after tumour resection. Multiple revisions, however, were seen only in patients with and due to tumour recurrence.

In the group of patients with postsurgical complications, revisions were required to treat, further conjunctival insufficiencies, recurrence of a tenon's cyst and to remove symblephara.

\section{DISCUSSION}

Autologous oral mucosal grafts are a viable option for the treatment of various ocular surface and lid disorders. In addition, OMG can be used to treat a broad range of postsurgical complications involving defects of the conjunctiva. The rate of complications is generally low, although a higher rate of revisions is required in patients with cicatricial ocular surface diseases.

In our clinic, the most common indication for $\mathrm{OMG}$ was ocular surface and fornix reconstruction in patients after tumour resection, and in particular, squamous cell carcinoma and malignant melanoma. Although basal cell carcinoma is the most common tumour of the eyelid, it

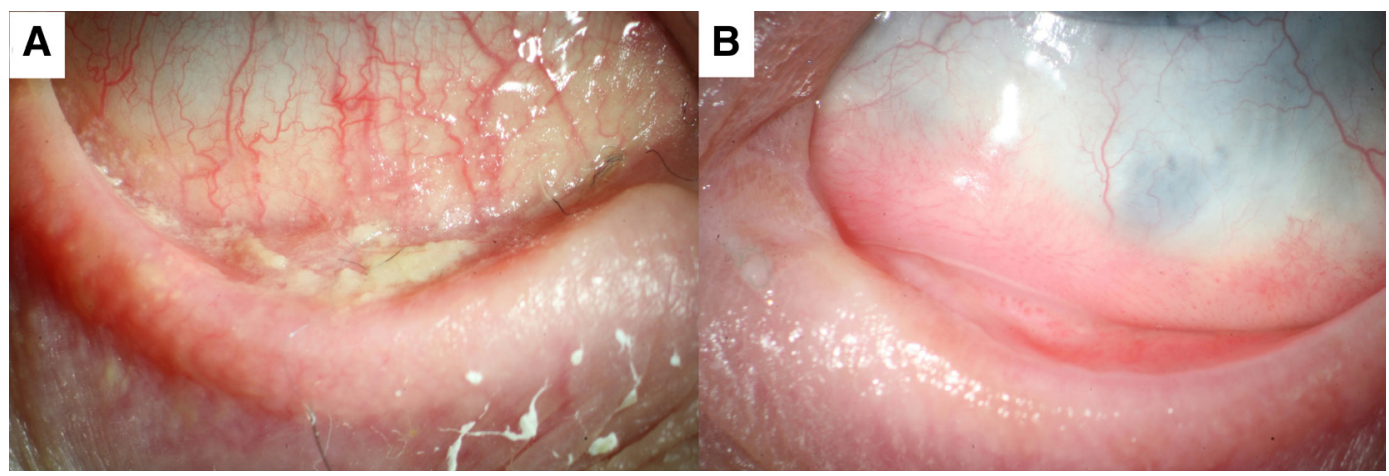

Figure 4 Fornixreconstruction with OMG in Steven-Johnson syndrome. OMG, oral mucosa grafting. 


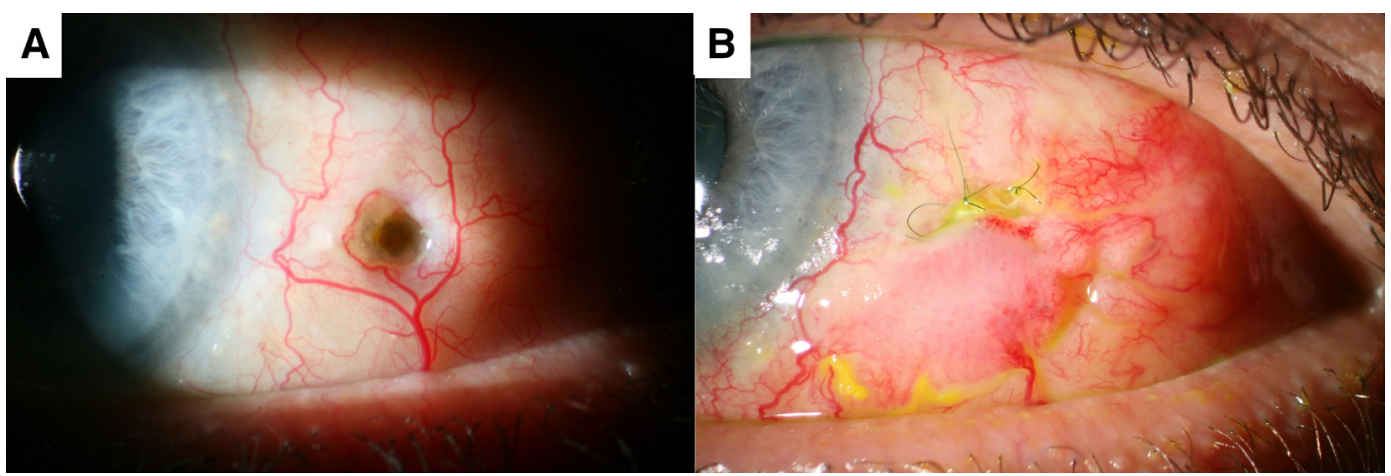

Figure 5 Scleromalacia of unknown origin patched with OMG. OMG, oral mucosa grafting.

rarely requires OMG if the eyelid can be reconstructed without large damage to the conjunctiva. In contrast, we generally combine resection of conjunctival tumours with OMG. Our experience shows that although the absolute number of complications was highest in this group of patients, the relative rate was considerably lower than in patients with cicatricial surfaces diseases or postenucleation socket syndrome. The latter could be due to the fact that conjunctival defects as a result of tumour resection are, with the exception of a very large tumour, smaller in size which could facilitate healing and reduce complications. The most common complication in OMG after tumour resection was symblephara, which occurred in almost every fifth patient, although most of them did not require revision surgery. In fact, the most common reason for revision surgery in this group of patients was a tumour recurrence. In the absence of tumour recurrence, OMG did not require a revision procedure.

When considering tumour recurrence in the usage of $\mathrm{OMG}$, one has to consider the possibility that recurrence can occur underneath the graft. In such cases, due to the thickness of the graft, OMG could conceal a tumour and noticing tumour recurrence is delayed. ${ }^{27}{ }^{28}$ In this study, we did not compare OMG with other, thinner tissues such as amniotic membrane and hence cannot comment on a possible delay in diagnosis. The low rate of tumour recurrence and the absence of tumour recurrence underneath the graft, however, suggest that OMG is a safe method after tumour excision.

The second most common indication for OMG in this study was surgery-related complications. Pterygium is known to recur even after conjunctival autografting in up to $47 \%$ of cases $^{10}$ and it was the most common indication

\begin{tabular}{|c|c|c|}
\hline Diagnosis & One revision & $>1$ revision \\
\hline Enucleation & $5(29 \%)$ & $3(17 \%)$ \\
\hline Cicatricial ocular surface diseases & $3(43 \%)$ & $1(15 \%)$ \\
\hline Trauma & $2(30 \%)$ & 0 \\
\hline Other & $1(10 \%)$ & 0 \\
\hline Surgical complications & $2(11 \%)$ & 0 \\
\hline Tumour & $11(15 \%)$ & $3(4 \%)$ \\
\hline
\end{tabular}

for OMG in the group of surgery-related complications. In this study, we did not see any recurrence after OMG grafting, similar to Trivedi et al showing no pterygium recurrence after treating 140 cases with $\mathrm{OMG}^{29}$

The treatment of conjunctival deficiencies as a result of complex glaucoma surgery can also successfully be treated using OMG. ${ }^{1}$ A leaking trabeculectomy bleb can be a complication of trabeculectomy and it has been successfully reconstructed using OMG. ${ }^{16}$ In this study, we show positive results when using OMG in the treatment of leaking blebs and in patients treated for tenon's cysts as a result of trabeculectomy. In these patients, the cyst was removed, and the bleb was successfully reconstructed using OMG, which required a revision in only one case.

The implantation of a glaucoma aqueous drainage device can lead to conjunctival deficiencies or even erosions. ${ }^{17}$ Rootman et al used a combination of lamellar corneal grafts covered with OMG to repair the defects. ${ }^{17}$ Due to its simplicity, we prefer OMG grafting to patch small conjunctival deficiencies, which repaired all defects successfully and required only one revision procedure. This suggests that simple OMG is an adequate technique for the treatment of such complications.

Besides glaucoma surgery, OMG can also be useful in the treatment of complications associated with retinal surgery. OMG has been used to manage exposed silicone retinal explants, ${ }^{18}$ a complication not seen in this study. We used OMG only in patients with scarred conjunctiva resulting from multiple retinal procedures. OMG was suitable for the patching of the conjunctival defects and no revisions were required.

Postenucleation socket syndrome with orbital volume deficit has been treated with dermis fat graft alone or in combination with $\mathrm{OMG} .^{30}$ Dermis fat grafting is frequently used in our clinic to fill up ocular volume deficiency and additionally to achieve deeper fornices in cases of symblephara. Our experience shows that dermis fat grafting alone was most effective with regard to an adequate compensation of the volume deficit but that in more complex postenucleation socket syndromes with pronounced symblephara, a revision surgery was required because of insufficient fornix depth. This could indicate that more complex postenucleation syndromes might be best treated using a two-step procedure, consisting of a 
replacement of the volume deficit, followed by a second surgery using OMG to reconstruct the fornix.

Insufficient conjunctival fornix depth and postenucleation socket syndrome are common in anophthalmic patients, impairing the adequate position of prosthesis. ${ }^{31}$ Increasing the depth of the inferior fornix, thereby augmenting the conjunctival surface area can be achieved with $\mathrm{OMG}^{31}$ and this can improve the fit of the prosthesis. ${ }^{5}$ We used this procedure successfully in patients with inadequate fornix depth, who presented themselves because of an ill-fitting prosthesis. Revisions due to inadequate fornix depth were only required in two cases. Nevertheless, if fornix reconstruction had to be performed on anophthalmic patients who had suffered from trauma, the revision rate was considerably higher and various subsequent procedures were required. In fact, revision rates in these patients were similar to revision rates seen in patients with cicatricial ocular surface disease. This could indicate that OMG in patients with symblephara as a result of trauma has a worse prognosis. Using nasal tissue could be more suitable for this group of patients. ${ }^{23}$ Supposedly, nasal mucosa contains goblet cells that add to the lubrication of the eye, which could impede the development of new symblephara.

Similar to what was seen in patients with symblephara due to trauma, conditions that lead to extensive symblephara may have a worsened prognosis after OMG. We performed symbelpharolysis in patients with ocular pemphigoid and Steven-Johnson syndrome. These groups of patients required more revisions than any other group and they had the highest rate of postoperative symblephara. After reviewing long-term results, Heiligenhausen et al, concluded that OMG should not be performed in patients with severe ocular pemphigoid. ${ }^{12}$ The postoperative outcome seen in this study also suggests that oral tissue might not be an adequate graft material in patients with ocular pemphigoid. We assume that a lack of lubrication contributed to the higher revision rate. Again, using a tissue with a mucine production such as nasal mucosa ${ }^{24}$ or labial salivary gland transplantation ${ }^{25}$ could reduce revision rate and might lead to better outcomes.

In conclusion, OMG is the most effective treatment for a wide range of ocular conditions involving conjunctival defects. OMG after tumour resection or prior to surgical intervention has few postoperative complications and seldom requires revision procedures. Similarly, OMG revision rates are low when used in the process of a fornix reconstruction in patients with postenucleation socket syndrome. In contrast, conjunctival defects as a result of trauma or cicatricial surface diseases seem less suitable for OMG. Here, alternative graft tissue or treatment options should be considered.

Acknowledgements DP is a participant in the BIH-Charité Clinician Scientist Program funded by the Charité - Universitätsmedizin Berlin and the Berlin Institute of Health. We acknowledge support from the German Research Foundation (DFG) and the Open Access Publication Funds of Charité - Universitätsmedizin Berlin.

Contributors DP: data collection, concept, implementation, data analysis and interpretation, writing manuscript, submission of the manuscript. CvS: implementation, data collection, interpretation and critical review of the manuscript. EB: implementation, concept, interpretation and critical review of the manuscript.

Funding The authors have not declared a specific grant for this research from any funding agency in the public, commercial or not-for-profit sectors.

Competing interests None declared.

Patient consent for publication Not required.

Provenance and peer review Not commissioned; externally peer reviewed.

Data availability statement Data are available upon request

Open access This is an open access article distributed in accordance with the Creative Commons Attribution Non Commercial (CC BY-NC 4.0) license, which permits others to distribute, remix, adapt, build upon this work non-commercially, and license their derivative works on different terms, provided the original work is properly cited, appropriate credit is given, any changes made indicated, and the use is non-commercial. See: http://creativecommons.org/licenses/by-nc/4.0/.

ORCID iD

Daniel Pilger http://orcid.org/0000-0003-3397-8139

\section{REFERENCES}

1 Grixti A, Malhotra R. Oral mucosa grafting in periorbital reconstruction. Orbit 2018;37:411-28.

2 Mai C, Bertelmann E. Oral mucosal grafts: old technique in new light. Ophthalmic Res 2013;50:91-8.

3 Bowen Jones EJ, Nunes E. The outcome of oral mucosal grafts to the orbit: a three-and-a-half-year study. Br J Plast Surg 2002;55:100-4.

4 Karesh JW, Putterman AM. Reconstruction of the partially contracted ocular socket or fornix. Arch Ophthalmol 1988;106:552-6.

5 Kim CY, Woo YJ, Lee SY, et al. Postoperative outcomes of anophthalmic socket reconstruction using an autologous buccal mucosa graft. J Craniofac Surg 2014;25:1171-4.

6 Klein M, Menneking H, Bier J. Reconstruction of the contracted ocular socket with free full-thickness mucosa graft. Int J Oral Maxillofac Surg 2000;29:96-8.

7 Nasser QJ, Gombos DS, Williams MD, et al. Management of radiation-induced severe anophthalmic socket contracture in patients with uveal melanoma. Ophthalmic Plast Reconstr Surg 2012;28:208-12.

8 deSousa J-L, Leibovitch I, Malhotra R, et al. Techniques and outcomes of total upper and lower eyelid reconstruction. Arch Ophthalmol 2007;125:1601-9.

9 Sakai S. Marginal eyelid reconstruction with a composite skin-muscle-mucosa graft from the lower lip. Ann Plast Surg 1993;30:445-8.

10 Forbes J, Collin R, Dart J. Split thickness buccal mucous membrane grafts and beta irradiation in the treatment of recurrent pterygium. $\mathrm{Br}$ J Ophthalmol 1998;82:1420-3.

11 Hartman DC. Use of free grafts in correction of recurrent pterygia, pseudopterygia and symblepharon. Calif Med 1951;75:279-80.

12 Heiligenhaus A, Shore JW, Rubin PA, et al. Long-Term results of mucous membrane grafting in ocular Cicatricial pemphigoid. Implications for patient selection and surgical considerations. Ophthalmology 1993;100:1283-8.

13 Shore JW, Foster CS, Westfall CT, et al. Results of buccal mucosal grafting for patients with medically controlled ocular Cicatricial pemphigoid. Ophthalmology 1992;99:383-95.

14 Kheirkhah A, Ghaffari R, Kaghazkanani R, et al. A combined approach of amniotic membrane and oral mucosa transplantation for fornix reconstruction in severe symblepharon. Cornea 2013;32:155-60.

15 Kheirkhah A, Blanco G, Casas V, et al. Surgical strategies for fornix reconstruction based on symblepharon severity. Am J Ophthalmol 2008;146:266-75.

16 Rootman DB, Kumar NL, Rootman DS, et al. Buccal mucous membrane for the reconstruction of complicated leaking trabeculectomy blebs. J Glaucoma 2010;19:270-4.

17 Rootman DB, Trope GE, Rootman DS. Glaucoma aqueous drainage device erosion repair with buccal mucous membrane grafts. $J$ Glaucoma 2009;18:618-22.

18 Murdoch JR, Sampath R, Lavin MJ, et al. Autogenous labial mucous membrane and banked scleral patch grafting for exposed retinal explants. Eye 1997;11:43-6.

19 Basu S, Pillai VS, Sangwan VS. Mucosal complications of modified osteo-odonto keratoprosthesis in chronic Stevens-Johnson syndrome. Am J Ophthalmol 2013;156:867-73. 
20 Ziai S, Rootman DS, Slomovic AR, et al. Oral buccal mucous membrane allograft with a corneal lamellar graft for the repair of Boston type 1 keratoprosthesis stromal melts. Cornea 2013;32:1516-9.

21 Tao JP, Luppens D, McCord CD. Buccal mucous membrane graftassisted lacrimal drainage surgery. Ophthalmic Plast Reconstr Surg 2010;26:39-41.

22 Wang S, Tian Y, Zhu H, et al. Tenonplasty combined with free oral buccal mucosa autografts for repair of Sclerocorneal melt caused by chemical burns. Cornea 2015;34:1240-4.

$23 \mathrm{Kim} \mathrm{JH}$, Chun YS, Lee SH, et al. Ocular surface reconstruction with autologous nasal mucosa in Cicatricial ocular surface disease. Am J Ophthalmol 2010;149:45-53.

24 Wenkel H, Rummelt V, Naumann GO. Long term results after autologous nasal mucosal transplantation in severe mucus deficiency syndromes. Br J Ophthalmol 2000;84:279-84.

25 Marinho DR, Burmann TG, Kwitko S. Labial salivary gland transplantation for severe dry eye due to chemical burns and Stevens-Johnson syndrome. Ophthalmic Plast Reconstr Surg 2010;26:182-4.
26 Sant' Anna AEBPP, Hazarbassanov RM, de Freitas D, et al. Minor salivary glands and labial mucous membrane graft in the treatment of severe symblepharon and dry eye in patients with StevensJohnson syndrome. Br J Ophthalmol 2012;96:234-9.

27 Goktas SE, Katircioglu Y, Celik T, et al. Surgical amniotic membrane transplantation after conjunctival and limbal tumor excision. Arq Bras Oftalmol 2017;80:242-6.

28 Palamar M, Kaya E, Egrilmez S, et al. Amniotic membrane transplantation in surgical management of ocular surface squamous neoplasias: long-term results. Eye 2014;28:1131-5.

29 Trivedi LK, Massey DB, Rohatgi R. Management of pterygium and its recurrence: by grafting with mucous membrane from the mouth. Am $J$ Ophthalmol 1969;68:353-4.

30 Molgat YM, Hurwitz JJ, Webb MC. Buccal mucous membrane-fat graft in the management of the contracted socket. Ophthalmic Plast Reconstr Surg 1993;9:267-72.

31 Dortzbach RK, Callahan A. Advances in socket reconstruction. Am J Ophthalmol 1970;70:800-13. 